\begin{tabular}{|c|c|}
\hline & $\begin{array}{l}\text { International Journal of Trend in Scientific } \\
\text { Research and Development (IJTSRD) }\end{array}$ \\
\hline 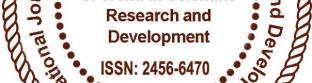 & International Open Access Journal \\
\hline 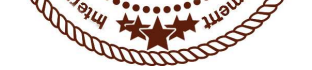 & ISSN No: 2456 - 6470 | www.ijtsrd.com | Volume - 2 | Issue - 2 \\
\hline
\end{tabular}

\title{
Smart Grid Infrastructure for Efficient Power Consumption Using Real Time Pricing Algorithm
}

\begin{abstract}
S. Varun Kumar
Department of Instrumentation and Control Engineering, St. Joseph's College of Engineering, Chennai, India
\end{abstract}

\author{
S. M Jayasurya \\ Department of Instrumentation and Control \\ Engineering, St. Joseph's College of Engineering, \\ Chennai, India
}

\section{ABSTRACT}

Electricity supply do not always satisfy customers' demand, which results in peak demand periods. When demand is at its peak, electricity providers have to react to meet the demand and avoid interruptions by boosting the capacity which is costly and not always possible. In addition to fluctuation in demand, price of electricity production changes continuously due to the variation in resources used for production over periods. Yet, the consumers pay the same price for the electricity unit both in on-peak and off-peak periods. A proposed solution would be the use of real time pricing (RTP) of electricity. The end-users will be involved in the electric grid and will have control on the consumption over different periods either by reducing or by shifting it to off-peak periods as a reaction to RTP. The results obtained prove that not only the electric utility, but also, the subscribers will benefit. Comparing the results of RTP algorithm to a scenario where price is fixed, we notice that the aggregate utility of every user is higher using RTP algorithm. Along with RTP algorithm we would like to suggest Distributed algorithm that automatically manages the smart meter and the electricity provider interactions. The results from the simulation shows that the proposed RTP algorithm and distributed algorithm can potentially benefit both customer and the electricity providers.
Keywords: Real time pricing algorithm, Distributed algorithm, Smart grids, Matlab.

\section{OBJECTIVE FUNCTION}

Our objective is to maximize the satisfaction of the subscribers to the grid and minimize the number of units that should be produced by the electric utility and to reduce the consumer cost for the electricity expenditure. The two optimization problems can be merged to one maximization problem that is to maximize the overall welfare

\section{CHALLENGES}

It is believed that dynamic pricing inflicts harm on low income consumers, seniors, people with disabilities, and people with young children, and small businesses These consumers are unable to curtail peak period usage because they have very little connected load to begin with. Therefore, the greatest barriers in implementation of dynamic pricing are legislative and regulatory, deriving from state efforts to protect retail customers from the vagaries of competitive markets. "The project caters to this barrier in implementation of dynamic pricing by showing substantial monetary gains for residential consumers (which constitute the families, low income consumers etc.) by adopting 
the Real Time Pricing mechanism for calculation of electricity charges".

Real-time price is the most ideal pricing mechanism in power market. Therefore, study on real-time price algorithm has profound theoretical and practical significance in smart grid. In this paper, we propose an improved real-time pricing algorithm

\section{ADVANCED METERING INFRASTRUCTURE}

Traditionally, electricity consumption for residential consumers has been recorded through bulk usage meters over a given period (typically 30 days) with the advent of smart meter technology, utilities can record this consumption as often as every 15 minutes

Smart meters enable consumers monitor their load pattern and schedule it optimally for cost savings and reduced strain on the grid. Despite the promise of substantial economic gains, the deployment of dynamic pricing for residential consumers has been remarkably tepid.

\section{EXECUTION OF RTP ALGORITHM}

In RTP, the retail price of electricity change at several predetermined time intervals during the same day. The electricity provider communicates the price continuously to the users using a 2-way communication system. The users communicate their consumption preferences and behaviour, while the utility sends the price. Energy consumption controllers within the smart meters take care of running the algorithm.

\section{EXECUTION OF RTP ALGORITHM}

In RTP, the retail price of electricity change at several predetermined time intervals during the same day. The electricity provider communicates the price continuously to the users using a 2-way communication system. The users communicate their consumption preferences and behaviour, while the utility sends the price. Energy consumption controllers within the smart meters take care of running the algorithm.

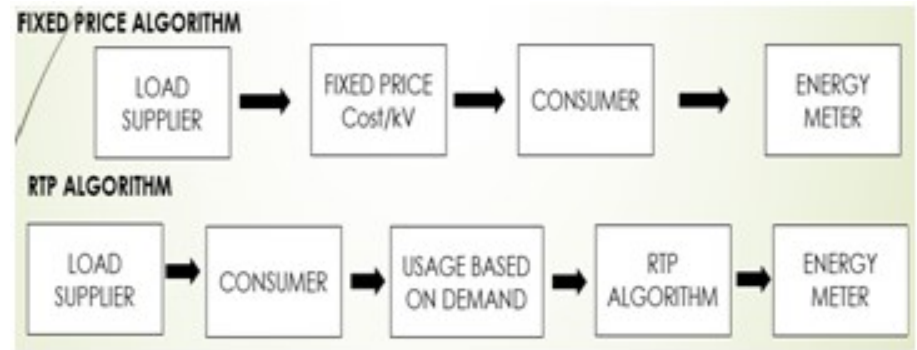

Figure 1. Block diagram of fixed price algorithm and RTP algorithm

\section{RESULTS}

The algorithms for both RTP and fixed cost pricing will be run 24 times a day. Every time the optimization problems are solved inside the "for loop", two vectors of solutions are obtained; one for every algorithm. We store the obtained vectors inside matrices that will be used for data visualization

\section{A) REAL-TIME-PRICING}

Assuming that we have 10 users subscribed to the grid and one cost to determine, and knowing that the algorithms will be run 24 times: the output will be a matrix of size $11 * 24$

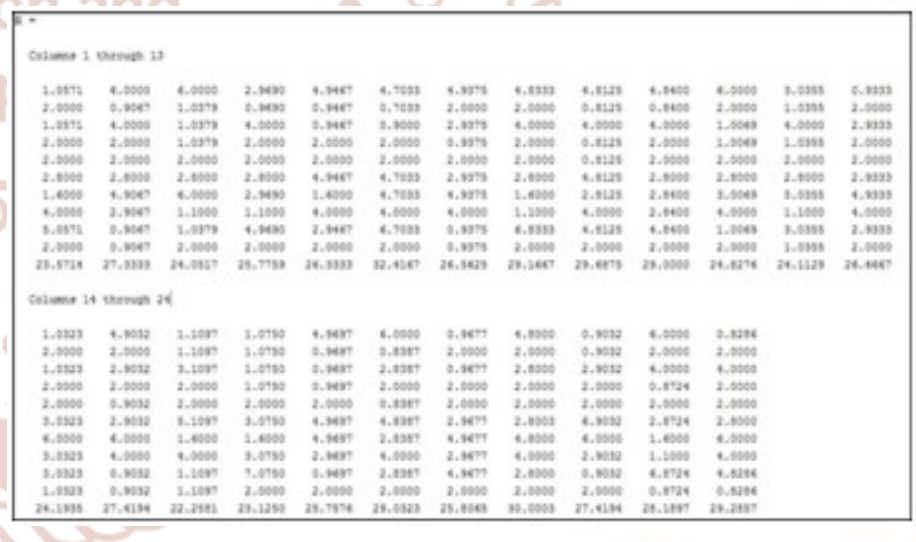

Figure 2. Output using RTP Algorithm. 


\section{B) FIXED COST}

Unlike the RTP algorithm, the price will be fixed. Thus, the output will be a matrix of size $10 * 24$

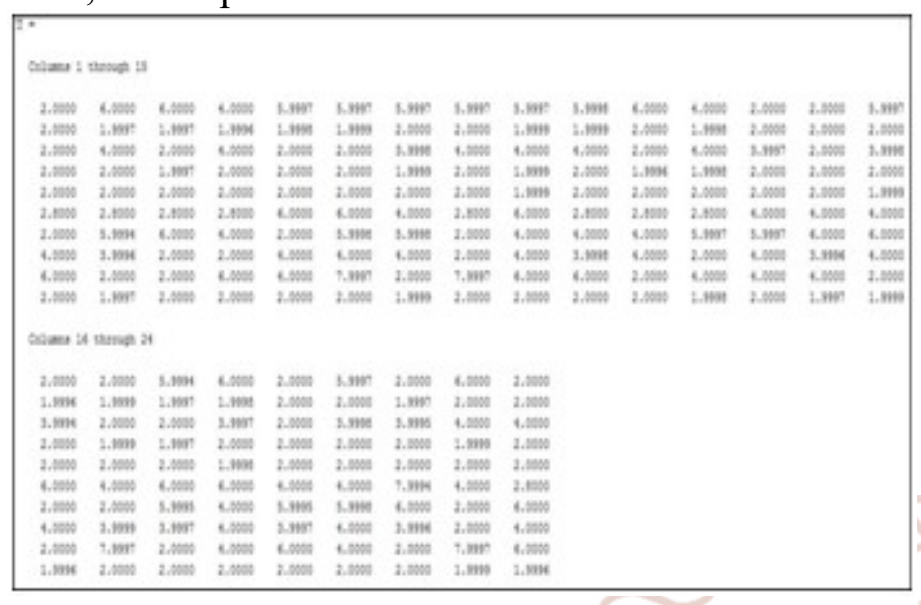

Figure 3. Output using Fixed Cost Algorithm.

\section{C) SIMULATION RESULTS}

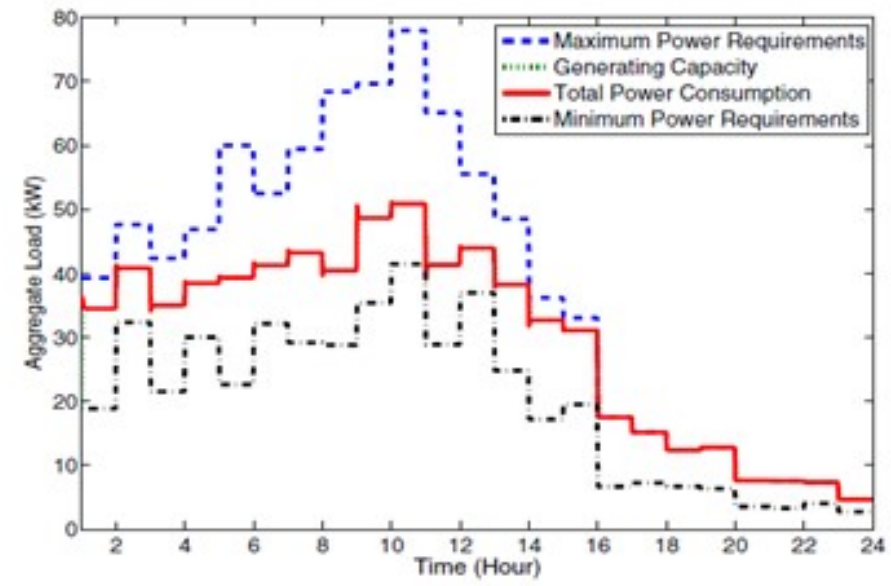

Figure 4. Total consumed power by one user when the proposed pricing algorithm is utilized

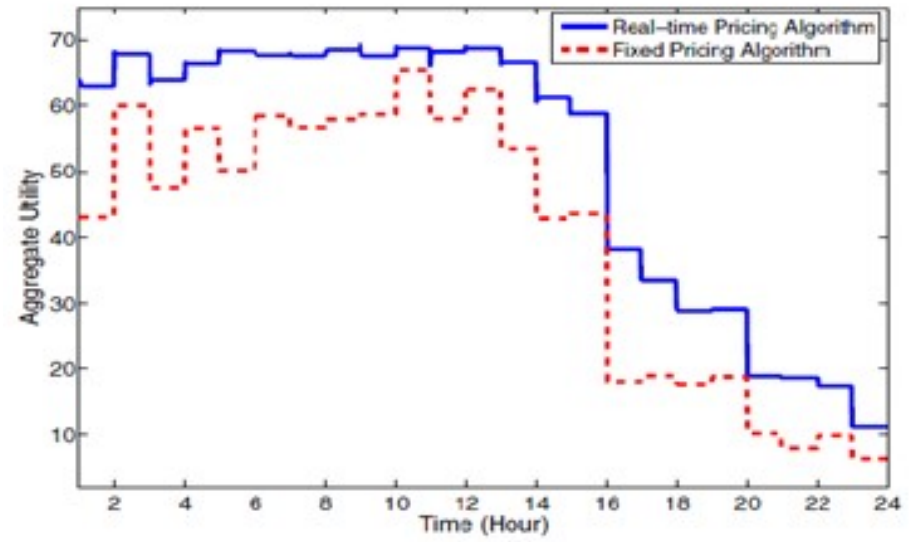

Figure 5. Aggregate utility of all 10 users when our proposed real-time pricing algorithm as well as a fixed pricing algorithm is utilized
From Figure 4. It is evident that the RTP Algorithm ensures the consumption is within the limits of the max and min power requirements

From Figure 5. We plotted in red the total consumptions of 10 user during every time interval with and without the RTP algorithm.

We conclude that using the preferences of users, RTP algorithm is proved to bring down the total consumption as it gives real time accurate cost per $\mathrm{kV}$ whereas the FPA gives a prefixed cost per $\mathrm{kV}$ for the users

\section{D) CONSUMER WELFARE:}

The following results shows the average consumer welfare with the real-time pricing algorithm and the fixed pricing algorithm.

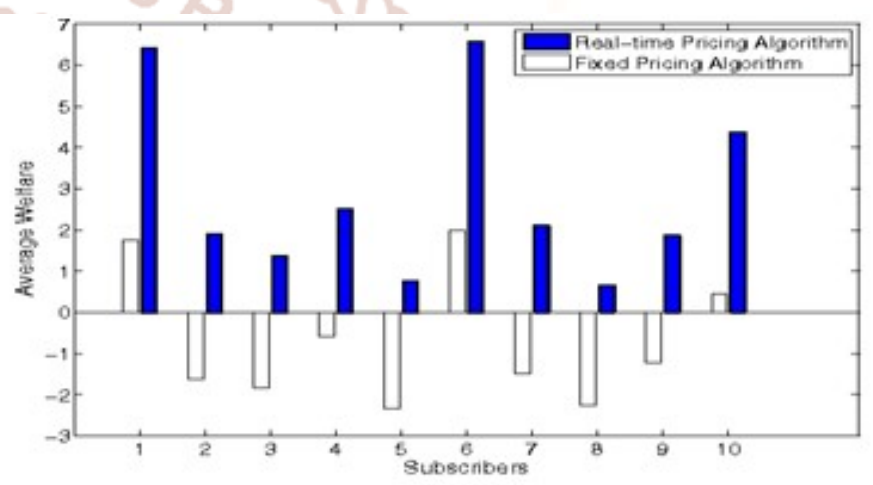

Figure 5. RTP VS FP algorithm

\section{E) $=64$ CONCLUSION}

Through the real-time pricing algorithm, it is now possible to provide the cost per $\mathrm{kV}$ based on the usage of the consumer rather than pre-fixing the cost per day by using the day ahead pricing method. The real time pricing algorithm proves to be very effective in absolutely making a model of the requirement approximately. Through the real-time pricing algorithm implementation, the cost for power is made constant through different sectors such as residential, industries and commerce based on their real-time usage of electricity. This ensures that the power expenditure does not exceed the limits thus ensuring profit to both the supplier and the consumer side. 
International Journal of Trend in Scientific Research and Development (IJTSRD) ISSN: 2456-6470

\section{REFRENCES:}

1) Real time electricity pricing based on Utility maximization for smart homes Written by: Salim el Kohen

2) Journal of Power and Energy Engineering, 2015, 3, 240-249 Published Online April 2015 in SciRes.

3) Haoxiang Chu, Da Xie, Yucheng Lou, Minxia Yang, Yu Zhang, "Information flow and its fusion of EV's intelligent integrated station", Electricity Distribution (CICED) 2014 China International Conference on, pp. 14251429, 2014, ISSN 2161-749X.

4) Tianyang Zhao, LeiLei Zhang, Wenxia Liu, Jianhua Zhang, ZongQi Liu, "Centralized spatial and temporal decomposition charging strategy for electric vehicles: A bi-level optimization approach", Transportation Electrification Asia-Pacific (ITEC AsiaPacific) 2014 IEEE Conference and Expo, pp. 1-6, 2014.

5) Thomas Gaonac'h, Martin Hennebel, Jing Dai, Jean-Claude Vannier, Ibrahim Mohand-Kaci,
"Assessing distribution line reinforcement costs due to Plug-in Electric Vehicle charging", European Energy Market (EEM) 2014 11th International Conference on the, pp. 1-5, 2014, ISSN 2165-4093.

6) Weixuan Lin, Eilyan Bitar, "Decentralized control of distributed energy resources in radial distribution systems", Smart Grid Communications (SmartGridComm) 2016 IEEE International Conference on, pp. 296301, 2016.

7) Mahnoosh Alizadeh, Yuanzhang Xiao, Anna Scaglione, Mihaela van der Schaar, "Dynamic Incentive Design for Participation in Direct Load Scheduling Programs", Selected Topics in Signal Processing IEEE Journal of, vol. 8, pp. 11111126, 2014, ISSN 1932-4553.

8) Mostafa F. Shaaban, E. F. El-Saadany, "Accommodating High Penetrations of PEVs and Renewable DG Considering Uncertainties in Distribution Systems", Power Systems IEEE Transactions on, vol. 29, pp. 259-270, 2014, ISSN 0885-895

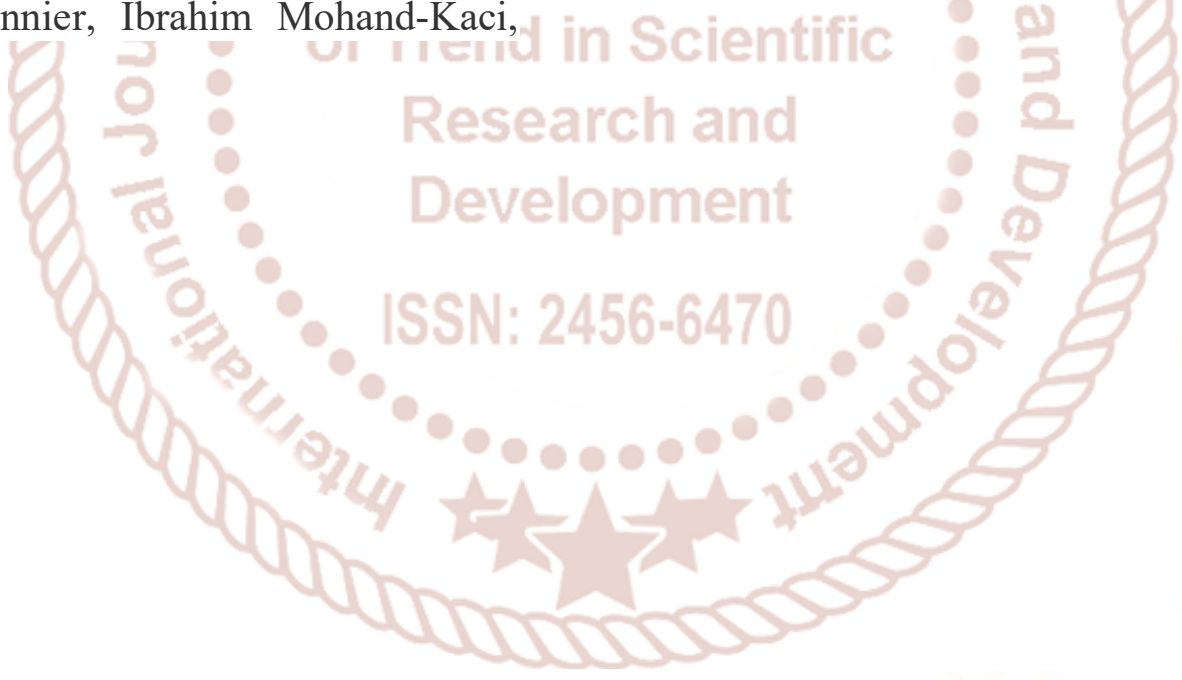

